\title{
A PRE-OPERATIVE MYDRIATIC REGIME USING A SINGLE APPLICATION OF TROPICAMIDE NOVEL OPHTHALMIC DELIVERY SYSTEM AND GUTTAE PHENYLEPHRINE 10\%
}

\author{
C. K. PATEL ${ }^{1}$, T. A. BUI ${ }^{2}$, G. GREGARIOU ${ }^{2}$, S. PEREIRA ${ }^{2}$, A. CHOPDAR $^{2}$ and B. K. McLEOD ${ }^{2}$ \\ Redhill
}

\begin{abstract}
SUMMARY
Tropicamide Novel Ophthalmic Delivery System (NODS) and guttae (g.) phenylephrine $10 \%$ was applied once, 2 hours before cataract surgery, as an alternative to our standard pre-operative regime of $\mathbf{g}$. cyclopentolate $1 \%$ and g. phenylephrine $10 \%$ used four times before surgery. The two treatment groups were compared using a randomised, prospective, observermasked study design. The horizontal pupil diameter was significantly smaller using the new regime but the per-operative decrease in diameter was not significantly different, suggesting that surgical miosis was not influenced by reducing the number of mydriatic applications. There was no difference in the subjective grading of the pupil, suggesting that adequate mydriasis suitable for cataract surgery was obtained using the alternative regime. No major complications were documented in relation to the use of NODS. We discuss why less intensive mydriasis is likely to be as efficacious and describe its potential advantages.
\end{abstract}

The traditional practice for achieving pre-operative mydriasis, in this unit, has been to use four drops of cyclopentolate $1 \%$ and phenylephrine $10 \%$ 1-2 hours before cataract surgery. We have recently started using pre-operative diclofenac and feel that it has been useful in minimising surgically induced miosis. Following documentation that pupils remained well dilated during surgery even when there had been insufficient time to administer the full

From: ${ }^{1}$ Clinical Cataract Research Unit, Oxford Eye Hospital, Radcliffe Infirmary, Woodstock Road, Oxford OX2 6AW, UK; ${ }^{2}$ Department of Ophthalmology, East Surrey Hospital, Three Arch Road, Redhill, Surrey RH5 5RH, UK. The work in this project was carried out at the East Surrey Hospital.

Correspondence to: C. K. Patel, Clinical Cataract Research Unit, Oxford Eye Hospital, Radcliffe Infirmary, Woodstock Road, Oxford OX2 6AW, UK. mydriatic regime, we felt it was necessary to reconsider the use of such intensive mydriasis.

We formulated a mydriatic regime consisting of a single application of tropicamide Novel Ophthalmic Delivery System (NODS) and guttae (g.) phenylephrine $10 \%$ given 2 hours before surgery. Four drops of diclofenac were also given at half-hourly intervals starting 2 hours pre-operatively. The NODS resembles a fluorescein strip. It consists of a terminal polymeric film insert incorporating $125 \mu \mathrm{g}$ tropicamide. The film is introduced into the lower fornix, where it separates from the body of the strip as it is dissolved by tear fluid. The advantages of NODS are improved bioavailability, portability and the possibly lower systemic absorption compared with drops. ${ }^{1}$ The aim of the study was to compare the efficacy of this new regime with the usual one used in the unit, and to highlight any potential problems of using tropicamide NODS.

\section{METHOD}

After obtaining ethics committee approval (Ref No. $2064)$, all patients $(n=68)$ admitted over a period of 10 weeks for routine extracapsular or phacoemulsification cataract extraction were assessed for the study. Patients requiring general anaesthesia $(n=2)$, or failing to give informed consent $(n=2)$, as well as those with previous intraocular surgery, iritis, diabetes or pseudoexfoliation $(n=8)$, were excluded. Those remaining were randomly allocated, by nursing staff, to the usual $(n=26)$ or the new $(n=$ 30) mydriatic regime, using random permuted blocks $^{2}$ that ensure approximately equal numbers of patients are assigned to each treatment group. Observers documenting outcome measures were therefore masked with regard to the allocation of the treatments.

On admission Goldmann tonometry and biometry 
were performed after using g. oxybuprocaine $0.4 \%$ for topical anaesthesia. Twenty-four hours later (for routine admissions) or 1-6 hours later (for day cases) each patient was given the appropriate mydriatic regime, taken to the anaesthetic room, given two drops of tetracaine $0.5 \%$ followed by either a peribulbar anaesthetic (50:50 2\% lignocaine and bupivacaine $0.75 \%$ and 150 units of Hyalase) or retrobulbar anaesthetic (2\% lignocaine - $2 \mathrm{ml}$ retrobulbar and $3 \mathrm{ml}$ O'Brien block). Nurses were asked to record any problems associated with administering the NODS. Corneal transparency was assessed because of the potential for a difference in epithelial toxicity between the regimes. This difference could have been related to the greater half-life and hence corneal contact time of NODS compared with drops ${ }^{3}$ or to the fact that more drops were used in the older regime. Corneal clarity was graded by the surgeon as clear or impaired after optimal focussing and wetting of the cornea prior to incising the limbus. Either standard endocapsular or phacoemulsification surgery using continuous curvilinear capsulorhexis was performed using sodium hyaluronate as the viscoelastic and balanced salt solution with 1:10 000 adrenaline as the irrigating solution. At the end of surgery subconjunctival gentamicin and betamethasone were administered and the eye padded and protected with a cartella shield.

The horizontal pupil diameter (HPD) was measured pre-operatively (A) and on day 1 following surgery (D) by two observers (C.K.P., T.A.B.) who compared the patient's pupil against circles of known diameter. Inter-observer variability was minimised by examining 10 patients before commencing the study. In $90 \%$ of patients the two observers' measurements differed by $1 \mathrm{~mm}$ or less. Needlepoint callipers were used by the surgeon and his or her assistant to measure the HPD before limbal incision (B) and following lens implantation and aspiration of viscoelastic (C). Where there was vitreous loss or accidental iris trauma, measurements $\mathrm{C}$ and $\mathrm{D}$ were omitted. The size of the pupil during the operation was graded by the surgeon as ideal, too small or overdilated.

For continuous variables, means were compared using a two-tailed Student's $t$-test, while proportions for nominal variables were compared using a chisquared test. A $p$ value of less than 0.05 was considered statistically significant.

\section{RESULTS}

Table I shows that the mean HPD was statistically smaller for the new regime at all peri-operative stages (B-D). The two groups were comparable because no statistical difference was found regarding the distribution of factors which could affect pupil size or subjective grading: age $(p=0.08)$, preoperative HPD $(p=0.3)$, iris colour $(p=0.18)$, type of local anaesthetic $(p=0.91)$, type of cataract surgery $(p=0.41)$, type of surgeon $(p=0.86)$ or the use of topical anaesthetic for biometry on the day surgery was performed $(p=0.13)$ (Table II). There was no significant difference between the groups when considering surgical miosis, defined as the mean percentage decrease in HPD from stage B to stage $C(p=0.33)$. Delayed miosis, defined as the

Table I. Mean horizontal pupil diameters and subjective grading for the two mydriasis regimes

\begin{tabular}{|c|c|c|c|}
\hline Variable & New regime $(n=30)$ & Old regime $(n=26)$ & $p$ value \\
\hline \multicolumn{4}{|l|}{ Mean pupil diameter $(\mathrm{mm} \pm \mathrm{SD})$} \\
\hline A. Before mydriasis & $\begin{array}{ll}3.3 \pm 0.8 & (n=17) \\
\mathrm{DP} & (n=13)\end{array}$ & $\begin{array}{ll}3.6 \pm 0.9 & (n=15) \\
\mathrm{DP} & (n=11)\end{array}$ & 0.3002 \\
\hline B. Before incision & $\begin{array}{ll}7.9 \pm 1.0 & (n=26) \\
\mathrm{DP} & (n=04)\end{array}$ & $\begin{array}{ll}8.6 \pm 1.1 & (n=23) \\
\mathrm{DP} & (n=03)\end{array}$ & 0.0296 \\
\hline C. After insertion of IOL & $\begin{array}{ll}6.4 \pm 1.3 & (n=23) \\
\mathrm{DP} & (n=04) \\
\mathrm{VL} & (n=02) \\
\text { ITE } & (n=01)\end{array}$ & $\begin{array}{ll}7.3 \pm 1.2 & (n=16) \\
\text { DP } & (n=05) \\
\text { VL } & (n=01) \\
\text { ITE } & (n=01) \\
\text { ITP } & (n=02) \\
\text { AC } & (n=01)\end{array}$ & 0.0333 \\
\hline D. First post-operative day & $\begin{array}{ll}3.1 \pm 0.6 \quad(n=22) \\
\text { DP } & (n=05) \\
\text { VL \& ITE as in C }\end{array}$ & $\begin{array}{l}5.1 \pm 0.9 \quad(n=17) \\
\text { DP } \quad(n=04) \\
\quad \text { VL-AC as in C }\end{array}$ & $2 \times 10^{-9}$ \\
\hline Surgical miosis & $\begin{array}{l}19.3 \% \quad(n=23) \\
\text { DP-ITE as in C }\end{array}$ & $\begin{array}{c}15.1 \% \quad(n=16) \\
\text { DP-AC as in C }\end{array}$ & 0.3308 \\
\hline Delayed miosis & $\begin{array}{l}\text { DO. } 9 \% \text {-ITE as in D } \\
\text { DP }\end{array}$ & $\begin{array}{l}\text { 40.2\% } \\
\text { DP-AC as in D }\end{array}$ & $6 \times 10^{-6}$ \\
\hline $\begin{array}{l}\text { Subjective pupil grade } \\
\text { ideal:too small:too large:not graded }\end{array}$ & $\begin{array}{c}\cdot 60 \%: 20 \%: 3 \%: 17 \% \\
(n=30)\end{array}$ & $\begin{array}{r}62 \%: 15 \%: 12 \%: 11 \% \\
(n=26)\end{array}$ & 0.6279 \\
\hline $\begin{array}{l}\text { Corneal clarity } \\
\text { clear:impaired }\end{array}$ & $\begin{array}{ll}87 \%: 3 \% & (n=27) \\
\mathrm{DP}=10 \% & (n=03)\end{array}$ & $\begin{array}{l}86 \%: 7 \% \\
\mathrm{DP}=7 \%\end{array}$ & 0.7468 \\
\hline
\end{tabular}

IOL, intraocular lens; DP, data missing from proforma; VL, vitreous loss; ITE, iris traumatised during extracapsular cataract extraction ITP, iris traumatised during phacoemulsification; AC, acetylcholine used during surgery. 
Table II. Factors which could affect pupil size or subjective grading in the two mydriasis regimes

\begin{tabular}{|c|c|c|c|}
\hline Variable & New regime $(n=30)$ & Old regime $(n=26)$ & $p$ value \\
\hline Mean age (years \pm SD) & $75.7 \pm 7.5$ & $79.3 \pm 7.4$ & 0.08 \\
\hline$\%$ males & $33 \%$ & $35 \%$ & 0.92 \\
\hline \multicolumn{4}{|l|}{ Iris colour ratio } \\
\hline blue/green:light brown:dark brown & $57 \%: 33 \%: 10 \%$ & $34 \%: 58 \%: 8 \%$ & 0.18 \\
\hline$\%$ retrobulbar anaesthetic & $30 \%$ & $27 \%$ & 0.91 \\
\hline$\%$ phacosurgery & $10 \%$ & $23 \%$ & 0.41 \\
\hline$\%$ operations by consultant & $43 \%$ & $42 \%$ & 0.86 \\
\hline$\%$ patients receiving g. oxybuprocaine $1-6$ hours before mydriasis & $60 \%$ & $38 \%$ & 0.13 \\
\hline
\end{tabular}

Abbreviations as in Table I.

mean percentage decrease in HPD from stage B to stage $\mathrm{D}$, was significantly greater for the new regime $(p=0.00006)$.

Despite these differences in pupil size, no difference was noted between groups for subjective pupil grade $(p=0.63)$ or corneal clarity $(p=0.75)$.

Nurses expressed no preference regarding the method of drug delivery. Two patients receiving NODS complained of discomfort associated with the oscillation of the strip of NODS. A further 3 patients complained of a persisting foreign body sensation even when the strip had dislodged. None of these patients had received topical anaesthetic for biometry on the day of surgery.

\section{DISCUSSION}

This study has found that tropicamide NODS is not associated with major complications and provides acceptable mydriasis in healthy eyes when used as described. Patients accustomed to drops may complain of transient discomfort and foreign body sensation which does not tend to occur if topical anaesthetic is used beforehand. It should, however, be borne in mind that drops may also cause stinging whch is alleviated by local anaesthetic. Prolonged contact of the NODS with the cornea did not appear to alter corneal clarity in a clinically significant way, although it must be emphasised that if there is a small difference in the incidence of corneal epithelial toxicity between the groups it might only be detected if a sample size larger than that used in this study were selected.

This study also shows that less intensive preoperative mydriasis does not interfere with subjective mydriasis or the degree of surgically induced miosis. Factors assisting mydriasis in both groups of patients have recently been published. Pre-operative nonsteroidal anti-inflammatory drugs (NSAIDs) such as flurbiprofen and diclofenac have proved useful in reducing surgical miosis, based on the assumption that prostaglandins are important mediators of pupillary constriction. ${ }^{4,5}$ Intraoperative adrenaline with balanced salt solution also safely maintains mydriasis. ${ }^{6}$ Other facets of modern cataract surgery that lend themselves to the use of less intensive mydriasis relate to the use of regional rather than general anaesthesia. Topical anaesthetic has, for example, been shown to enhance mydriasis. ${ }^{7}$ This

Table III. Mean horizontal pupil diameters and subjective grading for the $\times 2$ new regime and the old mydriasis regime

\begin{tabular}{|c|c|c|c|c|}
\hline \multirow{2}{*}{$\begin{array}{l}\text { Variable } \\
\text { Mean pupil diameter }(\mathrm{mm} \pm \mathrm{SD})\end{array}$} & \multicolumn{2}{|c|}{$\times 2$ new regime $(n=14)$} & Old regime $(n=26)$ & \multirow{2}{*}{$\frac{p \text { value }}{0.2346}$} \\
\hline & $\begin{array}{l}4.0 \pm 1.0 \\
\mathrm{DP}\end{array}$ & $\begin{array}{l}(n=11) \\
(n=03)\end{array}$ & $\begin{array}{ll}3.6 \pm 0.9 & (n=15) \\
\mathrm{DP} & (n=11)\end{array}$ & \\
\hline B. Before incision & $\begin{array}{l}8.4 \pm 0.8 \\
\mathrm{DP}\end{array}$ & $\begin{array}{l}(n=12) \\
(n=02)\end{array}$ & $\begin{array}{ll}8.6 \pm 1.1 & (n=23) \\
\mathrm{DP} & (n=03)\end{array}$ & 0.5835 \\
\hline C. After insertion of IOL & $\begin{array}{l}7.1 \pm 1.0 \\
\mathrm{DP}\end{array}$ & $\begin{array}{l}(n=11) \\
(n=03)\end{array}$ & $\begin{array}{ll}7.3 \pm 1.2 & (n=16) \\
\text { DP } & (n=05) \\
\text { VL } & (n=01) \\
\text { ITE } & (n=01) \\
\text { ITP } & (n=02) \\
\text { AC } & (n=01)\end{array}$ & 0.7581 \\
\hline D. First post-operative day & $\begin{array}{l}3.6 \pm 0.8 \\
\text { DP }\end{array}$ & $\begin{array}{l}(n=10) \\
(n=04)\end{array}$ & $\begin{array}{l}5.1 \pm 0.9 \quad(n=17) \\
\text { DP } \quad(n=04) \\
\quad \text { VL-AC as in C }\end{array}$ & 0.0012 \\
\hline Mean surgical miosis & $19.3 \%$ & $(n=11)$ & $\begin{array}{l}15.1 \% \quad(n=16) \\
\text { DP-AC as in C }\end{array}$ & 0.9541 \\
\hline Mean delayed miosis & $60.9 \%$ & $(n=10)$ & $\begin{array}{l}40.2 \% \quad(n=17) \\
\text { DP-AC as in D }\end{array}$ & 0.0098 \\
\hline $\begin{array}{l}\text { Subjective pupil grade: } \\
\text { ideal:too small:too large:not graded }\end{array}$ & $72 \%: 0: 1$ & $\begin{array}{l}\%: 14 \% \\
(n=14)\end{array}$ & $\begin{array}{r}62 \%: 15 \%: 12 \%: 11 \% \\
(n=26)\end{array}$ & 0.1042 \\
\hline $\begin{array}{l}\text { Corneal clarity } \\
\text { clear:impaired }\end{array}$ & $100 \%: 0$ & $(n=14)$ & $\begin{array}{l}91 \%: 7 \% \\
D P=7 \%\end{array}$ & 0.3022 \\
\hline
\end{tabular}

Abbreviations as in Table I. 
may occur because of improved bioavailability that results from disruption of the corneal epithelium ${ }^{8}$ or because blepharospasm-related loss of mydriatic is reduced. Local anaesthetic used without dilating drops produces limited mydriasis for cataract surgery, presumably by reducing parasympathetic tone to the iris. ${ }^{9}$ It may also reduce the production of substance $\mathrm{P}$ by neurones of the trigeminal nerve. This neuropeptide may be an important putative surgical miotic in the human. ${ }^{10} \mathrm{~A}$ drug interaction between topical phenylephrine and NSAIDs may also have the potential to increase the bioavailability of phenylephrine by the formation of ion-pairs which are known to have better lipid solubility and hence cell membrane permeability. ${ }^{11}$

The advantages of fewer applications of mydriatic include reductions in systemic absorption and toxicity (a recognised complication of topical phenylephrine ${ }^{12}$ ), corneal toxicity, discomfort and expense. The smaller pupil found on day 1 may reduce the incidence of posterior synechiae ${ }^{13}$ and result in a more stable intraocular lens post-operatively. It is not possible to state whether it was fewer applications of mydriatics or the use of tropicamide rather than the longer-acting cyclopentolate which caused the smaller pupil. A study design with the same muscarinic receptor blocker in each group would clarify the matter. A larger delayed miosis found when using the new regime can be reconciled with the absence of a difference in surgical miosis between the groups by hypothesising that mediators of surgical miosis are only important arbiters of pupil size during surgery and the early post-operative period. By day 1 alphaadrenergic and cholinergic mechanisms become relatively more important. This would be consistent with the short half-life of prostaglandins, which tend to be produced only when the iris is traumatised. ${ }^{14}$

Following the results of this study we doubled the dose of mydriatic used in our new regime. In a consecutive series of 14 patients no significant difference in pupil diameter was found at all stages except for day 1 post-operatively (Table III). Again this difference was not accounted for by age $(p=$ $0.51)$, iris colour $(p=0.08)$, type of local anaesthetic $(p=0.22)$, surgery $(p=0.06)$, surgeon $(p=0.34)$ or use of topical anaesthesia before using mydriatics $(p$ $=0.87$ ). This finding would need to be confirmed by a randomised masked study involving a larger number of patients, but does suggest that it is possible to reduce the number of applications by $50 \%$ without affecting pupil behaviour during surgery.
For units carrying out a large proportion of their cataract surgery under local anaesthesia we recommend the consideration of less intensive mydriasis. This study has not determined whether this would also apply to eyes that have a tendency to dilate poorly.

Key words: Cataract extraction, Mydriasis, Tropicamide NODS.

\section{REFERENCES}

1. Kelly JA, et al. The relative bioavailability of pilocarpine from a novel ophthalmic delivery system and conventional eye drop formulations. $\mathrm{Br} \mathrm{J}$ Ophthalmol 1989;73:360-2.

2. Pocock SJ. Clinical trials: a practical approach Chichester: Wiley, 1991.

3. Fitzgerald $\mathrm{P}$, et al. Scintigraphic assessment of the precorneal residence of a new ophthalmic delivery system (NODS) in man. Int $J$ Pharmaceutics 1992;83:177-85.

4. Jackson H, Patel CK, Westcott M, Thompson GM, Mathalone B. Does topical flurbiprofen affect the pupillary response to acetylcholine? Eye 1994;8: 329-31.

5. Condon PI, Watson A, Gupta A, Kinsella M. The inhibiting effects of diclofenac sodium on operative miosis in phaco surgery. Poster presentation at the annual congress of the Royal College of Ophthalmologist, Guernsey, 1994.

6. Corbett MC, Richards AB. Intraocular adrenaline maintains mydriasis during cataract surgery. $\mathrm{Br} \mathrm{J}$ Ophthalmol 1994;78:95-8

7. Apt L, Henrick A. Pupillary dilatation with single eyedrop mydriatic combinations Am J Ophthalmol 1980;89:553-9.

8. Boljka M, Kolar G, Vidensek J. Toxic side-effects of local anaesthetic on human cornea. $\mathrm{Br} \mathrm{J}$ Ophthalmol 1994; 78:386-9.

9. Princeton-Nadler M, Pavlis RJ. Wider,please! A study of pre-extraction pupillary dilatation. In: Emery JM, Paton D. Current concepts in cataract surgery: proceedings of third biennial cataract surgical congress. St Louis: C V Mosby, 1974:70-1.

10. Camras CB, Miranda OC. The putative role of prostaglandins in surgical miosis. Prog Clin Biol Res 1989;312:197-210.

11. Ashton P, Clark DS, Lee VH. A mechanistic study on the enhancement of corneal penetration of phenylephrine by flurbiprofen in the rabbit. Curr Eye Res 1992;11:85-90.

12. Fraunfelder FT, Scafidi AF. Possible adverse effects from topical ocular $10 \%$ phenylephrine. Am J Ophthalmol 1979;85:447-53.

13. Teimory M, Davey K, Marsh IB. Is post-cataract mydriasis necessary? Eye 1993;7:578-9.

14. Stryer L. Biochemistry. 3rd ed. New York: WH Freeman, 1988. 